\title{
Por Que ChaMar de MORTE O QUe É TRANSBORDAMENTO DE VIDA?
}

Por Cristina Mair Barros Rauter ${ }^{\star}$

MARTINS, A. Pulsão de morte? Por uma clínica psicanalítica da potência. Rio de Janeiro: UFRJ, 2009. 385 p.

\section{RESUMo}

Resenha da obra, destacando seus pontos principais no que se refere à problematização crítica do conceito freudiano de pulsão de morte a partir das filosofias de Nietzsche e Spinoza e da psicanálise winnicottiana.

Palavras-chave: psicanálise; pulsão de morte; Spinoza.

\section{WHY CALLING DEATH WHAT IS AN OVERFLOW OF LIFE?}

\begin{abstract}
A review underlining the principal aspects of the book: a critical approach to the Freudian concept of Death Instinct departing from the philosophies of Nietzsche and Spinoza and from the psychoanalysis of Winnicott.
\end{abstract}

Keywords: psychoanalysis; death instinct; Spinoza.

\footnotetext{
^ Psicóloga. Doutora em Psicologia (Psicologia Clínica) pela Pontifícia Universidade Católica de São Paulo. Professora associada III da Universidade Federal Fluminense, onde atua na pós graduação stricto sensu e na graduação em Psicologia. Endereço: Universidade Federal Fluminense, Instituto de Ciências Humanas e Filosofia. Campos do Gragoatá, Bloco O Sala 214. São Domingos, Niteroi, RJ - Brasil - CEP: 24220-350.

E-mail: rautercristinamair02@gmail.com
} 
A proposta do livro "Pulsão de morte? Por uma clínica psicanalítica da potência”, de André Martins, filósofo e psicanalista, é pensar criticamente a pulsão de morte, que podemos considerar como o mais paradoxal conceito da psicanálise e divisor de águas no que diz respeito às orientações filosóficas a partir das quais se pode reler o pensamento psicanalítico hoje, passados mais de 100 anos desde sua fundação.

Nessa postura experimental face aos conceitos da psicanálise, o autor segue uma orientação freudiana, nem sempre seguida pelos pós-freudianos: a de que a pulsão de morte é apenas de uma hipótese, e enquanto tal, é um conceito que busca explicar uma realidade, principalmente a realidade dos conflitos vividos pelos pacientes na clínica psicanalítica. Mas qual será a utilidade prática desse conceito? Para muitos e até mesmo para Freud em certos momentos de sua obra, ele não tem lugar na clínica, que lida sobre tudo com as forças de vida quando se trata de minorar o sofrimento psíquico dos pacientes. Para Winnicott (1994 apud MARTINS, 2009, p. 11), o conceito de pulsão de morte é um peso do qual ele quer aliviar Freud, que o carrega "com suas costas de atlas", como consta da epígrafe que abre o livro.

Talvez possamos considerar o conceito de pulsão de morte como anacrônico, se levarmos em conta o ambiente filosófico e científico atual, em especial nos campos da biologia, da física ou da ecologia. Em que apoiar uma concepção de que o vivo tende para a morte, se considerarmos, por exemplo, os desenvolvimentos atuais da biologia de Maturana e Varela, construída a partir da concepção de auto-poiesis e que possui, ela mesma, inequívoca proximidade com a causa sui de Spinoza e com a concepção de natureza desse filósofo, muito difundida atualmente a partir de Gilles Deleuze. Por outro lado, o cenário das discussões sobre a violência e a criminalidade contemporâneas é hoje dominado pela crença em tendências negativas que se expressariam em patologias individuais e coletivas e em soluções repressivas. Eis uma das razões para que a temática dessa obra se faça tão atual, ao empreender uma rigorosa avaliação crítica desse conceito: algumas soluções conservadoras para a questão da violência se apoiam inequivocamente na crença numa tendência para a destruição que estaria presente originariamente nas subjetividades. Até que ponto essas abordagens encontram embasamento no conceito freudiano de pulsão de morte é um a das questões que a leitura de Pulsão de Morte? permite esclarecer.

É em Spinoza e Nietzsche que estarão apoiadas as análises críticas do texto freudiano empreendidas neste livro, tendo Winnicott como o parceiro privilegiado no campo da psicanálise. No capítulo 1 a proposta do autor é realizar uma exegese do texto freudiano no que se refere à emergência do conceito de pulsão de morte, analisando as obras nas quais este conceito é tratado por Freud. Desde logo, problematizações mais gerais com relação à teoria das pulsões e às relações entre natureza e cultura são feitas. A apresentação exaustiva das teses freudianas conduz o leitor a uma importante revisão da segunda tópica freudiana bem como da metapsicologia. Neste capítulo, que é o mais extenso do livro, busca-se atentar para o que Freud "de fato escreveu", sem que isso implique em concordar com 
tudo o que ele diz, mas tendo ciência da letra do texto para avaliar o que seria interessante manter ou atualizar, modificar ou mesmo refutar, o que será feito em diversos momentos.

Como compreender o fato de que alguns pacientes parecem preferir a neurose à cura? Como compreender o sonho traumático, no qual se repete uma experiência tão desagradável como um acidente de automóvel ou uma agressão sofrida num assalto? Ou ainda outros fenômenos como a emergência de um prazer de matar que alguns indivíduos inequivocamente expressam, ou ainda a incapacidade de experimentar a felicidade e o prazer, que Freud descreveu quando observa que alguns pacientes parecem piorar justamente quando conquistam alguma coisa muito desejada? Para Freud, estes fenômenos evidenciaram a necessidade de incluir, entre os conceitos psicanalíticos, uma tendência primordial para morte. Por outro lado, muitas vezes veremos que é o próprio Freud quem aponta a possibilidade de outras leituras para esses fenômenos negativos que aparecem na clínica e que lhe permitiriam prescindir dessa explicação. Por exemplo: na neurose obsessiva e na melancolia o supereu é cruel na sua relação com o eu, e dirigindo-lhe severas críticas que produzem fortes sentimentos de culpa. Enquanto na neurose obsessiva o eu luta contra o supereu, na melancolia ele parece capitular, concordando com a culpa que lhe é imputada. Na histeria, o recalque atinge tanto os investimentos do eu com relação ao objeto quanto as próprias críticas do supereu, dando origem aos chamados sentimentos inconscientes de culpa. Com relação a essas diversas manifestações, adverte Freud (1923 Apud. Martins, 2009, p. 66): caberia "descobrir os impulsos recalcados que realmente se acham no fundo do sentimento de culpa". E neste momento, sublinha Martins (2009, p. 67): "chama-nos a atenção que até este ponto Freud em momento algum de sua pertinente análise precisasse falar de pulsão de morte... o que será acrescentado a partir de então.”

Vamos acompanhando diversos paradoxos do pensamento freudiano, nos quais a interpretação dada por Freud diverge daquela que, apoiados em sua própria teoria, poderíamos dar e que tornariam a hipótese de uma tendência destrutiva primordial desnecessária. Na célebre interpretação do jogo do carretel, Freud reconhece a potência da criança para construir, através do brincar, sua autonomia face à mãe. Por que razão Freud não se satisfaz com essa explicação e permanece buscando provas do funcionamento de "tendências além do princípio do prazer e mais primitivas que ele" que se expressariam nesse jogo? Mas não se trata no livro, em especial com relação a fenômenos clínicos, não tanto de refutar Freud, mas de colocar "um Freud contra outro", ao buscar construir uma perspectiva teórico-clínica que será explicitada no terceiro capítulo.

É em relação à questão da agressividade que as divergências com Freud se tornarão mais profundas. Para Martins é Winnicott quem permitirá ver de forma inequívoca, nos primeiros gestos espontâneos da agressividade infantil, não a manifestação de uma tendência originária para o negativo, mas sua expansão na direção do mundo. As manifestações destrutivas só poderão ser secundárias, 
nunca evidência de uma destrutividade originária. Elas estariam ligadas ao modo como o ambiente foi capaz de acolher o bebê em sua experiência originária de indiferenciação e dependência do mundo adulto.

Se o conflito psíquico é pensado por Freud principalmente a partir do modelo binário onde amor e ódio combatem, a perspectiva spinozista e nietzschiana que anima a leitura feita por André Martins da obra de Freud não cessa de apontar que a existência de sadismo, masoquismo, destrutividade e melancolia não são razões suficientes para imaginar um psiquismo penetrado por tendências à destruição, ou por uma culpabilidade entendida como experiência geral do psiquismo humano. A partir do conceito de reativo em Nietzsche, podemos pensar a transformação do que é ativo em reativo, do amor em ódio, sem a necessidade de postular nenhuma tendência originária para o negativo. As neuroses e psicoses confirmam o fato observado por Freud de que alguns podem experimentar as demandas pulsionais como perigos internos defendendo-se contra eles, mas isso não será verdade para todos os seres humanos. Alguns, os que tiveram um acolhimento inicial insuficiente, poderão de fato experimentar o desejo como perigoso e o meio ambiente como hostil.

O que perceberemos ao longo da leitura de Pulsão de Morte? é que esse conceito nasce muito mais das escolhas filosóficas feitas por Freud, principalmente a partir das filosofias de Schopenhauer, Kant, Platão ou mesmo de Hegel e de influências do romantismo alemão, do que dos achados clínicos. Do complexo de Édipo resulta a introjeção dos valore dos pais e a entrada na cultura humana. "A criança se tornaria um ser cultural por ação externa, por introjeção de um supereu e de um ideal de eu, de fora prepara dentro, do exterior cultural para o interior, até então somente natural". (Martins, 2009, p.76) Para Freud, tanto quanto para Kant, é quando não precisamos da autoridade externa - quando temos o policial em nós, como poderíamos dizer - é que amadurecemos. Antes de édipo, a criança estaria no reino natural, onde todos os desejos podem ser satisfeitos, segundo uma visão de natureza do romantismo alemão do qual Freud demonstra ser em boa parte herdeiro.

André Martins irá encontrar na oposição entre natureza e cultura a limitação fundamental que atravessa o pensamento psicanalítico. Utilizando-se da filosofia para pensar a psicanálise, propõe sua aproximação com outras filosofias: as de Spinoza, Nietzsche e Deleuze, para que se possa pensar a cultura em continuidade com a natureza.

Que deva existir sintonia do pensamento de Freud com o pensamento do seu tempo é inevitável, porém poderíamos nos perguntar por que o pensamento de Freud é tão estranho ao pensamento de Marx ou mesmo de Nietzsche, que podemos considerar também como pensamentos do seu tempo. Freud não crê numa gênese afetiva da vida social no sentido positivo e produtivo, aponta André Martins, ao comentar que é principalmente pela via do amor que os valores dos pais são adotados, não sem possibilidade de divergência. O pensamento social de Freud segue reafirmando uma negatividade presente nas coletividades. Para ele, em "O Futuro de Uma Ilusão", (FREUD, 1927) as massas são pouco afeitas ao 
trabalho e pouco inteligentes, além de facilmente dominadas por afetos incontroláveis, sendo a vida social pensada sempre a partir da necessidade de imposição de regras morais exteriores. A imposição de regras morais é para Freud, terapêutica, tanto do ponto de vista individual, como social. Em o "Eu e o Isso", ele assinala que, com o complexo de Édipo, os valores morais dos pais serão internalizados e dessa maneira, a criança que reedita o selvagem será "civilizada".

Freud parece pensar que quanto mais civilização ocidental houver, menos violência e guerras haverão, mesmo tendo vivido na pele a sangrenta primeira guerra mundial. Tal expectativa foi inteiramente desmentida pelos fatos, em especial depois do advento do nazismo, mas há ainda que pense que a civilização ocidental ou alguns países considerados como modelos de democracia têm a missão de difundir no mundo valores morais enquanto outras nações bárbaras ou inferiores são deles desprovidos. "É fácil a um bárbaro ser sadio, para homem cultural, a tarefa é árdua”. (FREUD, 1938 apud MARTINS, 2009, p. 211.)

À medida que avançamos na leitura do primeiro capítulo, descortinamos os diversos matizes nos quais se apresenta oposição natureza e cultura no pensamento freudiano. A concepção de cultura freudiana o aproximará de alguns pensadores de inequívoco viés conservador, na construção de uma certa concepção de natureza que já nos é distante e também de uma antropologia centrada na superioridade europeia sobre as demais nações e povos do mundo, que ainda subsiste nos dias atuais, embora já sem o prestígio dos tempos de Freud. Segundo tais concepções, a cultura europeia seria inequivocamente superior. Aliás, poderia ser considerada como "a cultura" e a ela caberia um papel de guia face às demais. Por outro lado, o animal no homem é o que explicaria a existência de uma tendência à destruição. Não podemos deixar de assinalar que tal afirmação não encontra nenhum respaldo na realidade, quando refletimos que certas formas de agressividade, como o genocídio em massa perpetrado contra membros de uma mesma espécie é algo específico do animal-humano, não sendo conhecido no mundo animal.

Paralelamente à oposição natureza e cultura, Freud também opõe corpo e mente. A existência humana estaria constantemente acossada por perigos externos, provenientes de uma natureza hostil, e de perigos internos, colocados pelas exigências pulsionais, sendo a sublimação um caminho possível, mas que implicaria numa transformação pulsional para que o desejo pudesse investir objetos não sexuais. Reduzindo o prazer à descarga sexual enquanto algo que se passa no corpo, Freud não pode compreender que criação possa ser uma experiência de prazer simultaneamente no corpo e na mente, sem que seja necessária qualquer transmutação.

No capítulo II serão analisadas as leituras contemporâneas da pulsão de morte, em especial as de Melanie Klein, Laplanche, Pontalis e Lacan, para citar os principais autores referidos. A seguir, leituras realizadas por autores brasileiros, como Joel Birman, Renato Mezan e Luis Cláudio Figueiredo, sem a pretensão de traçar, neste momento da obra, um panorama tão exaustivo como aquele traçado com relação a Freud, o que é deixado para obra futura. Para Martins, a maioria dos pós freudianos pretende a princípio explicar o que em Freud parece obscuro, 
mas chega a resultados díspares que se afastarão, mesmo que inadvertidamente, do que Freud propusera inicialmente. Por outro lado, todos parecem tomar a hipótese da pulsão de morte como algo definitivamente incorporado ao "arsenal" de conceitos psicanalíticos, parecendo não atentar que para o mestre se tratava apenas de uma hipótese. Será este um efeito da própria instituição psicanalítica, o da submissão à palavra do pai fundador ao ponto de se tornar seus "filhos" mais realistas que o rei? Se Melanie Klein faz um uso clínico do conceito que Freud não fizera, Lacan de certo modo mantém e aprofunda a dissociação entre natureza e cultura ao conceder à linguagem um papel central nessa diferenciação, sob a primazia do simbólico.

Joel Birman aparece como o único autor que supera a oposição freudiana entre Eros e civilização e que fornece outras bases para uma valorização do conceito de pulsão de morte como uma força que opera para além da representação. Mas mesmo em relação à leitura de Birman, permaneceria ainda uma questão: por que seguir nomeando como morte algo é um transbordamento de vida? Não que afirmar a univocidade do ser traga um mundo de calmaria ou de felicidade, pois o ambiente hostil que por certo "acolhe" muitos recém nascidos forja em alguns indivíduos, ou mesmo em muitos, a experiência de transbordamento de vida como negativa. No entanto, isso não pode ser visto como algo geral, que ocorreria em todos os indivíduos.

No capítulo III estará explicitada a perspectiva teórico-clínica do autor, que verá na pulsão a expressão de vida em estado de pulsação, sem a necessidade de colocar em seu registro nenhum objeto perdido originariamente. Que perspectivas clínicas poderão surgir a partir dos questionamentos feitos à psicanálise até aqui? Se o empreendimento freudiano estava inexoravelmente atravessado pela morte e pela negatividade, o autor acredita que é possível transformar ou dinamizar a psicanálise, "tornando-a atual e viva". Essa psicanálise se agencia com outras filosofias, com a arte, com a biologia e a física contemporâneas para a construção de uma clínica da afirmação da potência. Potência que não está mais referida à castração, já que "o oposto da onipotência não é a castração, mas a potência de agir"(MARTIN, 2009, p. 351). O plano coletivo e o plano individual não podem ser opostos, pois que a potência da criança presente no brincar é o que justamente a levará à experiência coletiva, configurando a vida social não como oposta à experiência individual, mas indissociável da mesma.

Nessa perspectiva, todas as formas do negativo aparecem como secundárias, reativas no sentido de Nietzsche ou imaginárias no sentido de Spinoza. Nessa a clínica a ética não está baseada na obediência a valores pretensamente universais, mas na experimentação e na expressão da diferença.

No isso, não haverá mais a luta entre pulsões de morte e pulsões de vida, mas o borbulhar da pulsão originária, impulsionando o indivíduo ao gesto espontâneo, a expandirse e assim, a criar seu espaço potencial e neste interagir com o mundo à sua maneira (MARTINS, 2009, p. 352). 
O empreendimento é corajoso, e a leitura do livro em si mesma constitui-se numa experiência de afirmação da potência do pensar, em seu projeto de levar a psicanálise a uma exploração da radicalidade de suas descobertas fundamentais no diálogo com outros saberes, projeto com o qual compartilho e que possui grande proximidade com o que costumo nomear como "clínica transdisciplinar".

\section{REFERÊNCIAS}

FREUD, S. O eu e o isso (1923). In: Obras Psicológicas Completas de Sigmund Freud. Rio de Janeiro: Imago, 1976. Edição Standard Brasileira. v. XIX, p. 23-79.

FREUD, S. O futuro de uma Ilusão. In: Obras Psicológicas Completas de Sigmund Freud. Rio de Janeiro: Imago, 1976. Edição Standard Brasileira. v. XXI, p. 81-178.

Recebido em: 18 de fevereiro de 2011 Aceito em: 04 de maio de 2011 